\title{
Psychodynamics of Medication Adherence in the Treatment of Psychiatric Patients
}

\author{
Myung Seon Song and Soo-Bong Jung \\ Department of Psychiatry, Keyo Hospital, Uiwang, Korea
}

\section{정신역동과 약물순응도}

\author{
송명선 · 정수봉 \\ 계요병원 정신건강의학과
}

\begin{abstract}
Medication adherence is instrumental for better treatment outcomes. However, many patients - especially psychiatric patients do not stick to their prescription. In this study, we analyzed the factors associated with treatment adherence and improvement using psychodynamic and psychotherapeutic techniques. The psychodynamic formulation in psychopharmacology can be used to improve medication adherence in most treatment settings. The components of the formulation include psychodynamic significance of medication and symptoms, transference, countertransference, and patient's attachment style. Even though the psychodynamic significance of medication varies with the patient, a few common features include medication as transitional object and self object. Both transference to the medication and the therapist involve adherence. Counter-transference can also alter the therapist's prescriptions. The psychodynamics of illness and symptoms may hinder the patient from taking medication. For example, the secondary gain of illness and patient's denial of mental illness complicate the treatment. The attachment style of patients can affect adherence as well. The patient with avoidant attachment style is less likely to follow the prescription. The therapist should deal with negative transferences and counter-transferences, which might hamper treatment. A warm and collaborative approach can help patients with an avoidant attachment style to accept pharmacologic treatment. In conclusion, the capacity of the therapist to assess the therapeutic relationship, determine the psychodynamic significance of the medication, and employ relevant therapeutic interventions is vital for improved medication adherence.

Psychoanalysis 2021;32(4):155-160
\end{abstract}

Keywords: Medication adherence; Psychopharmacology; Psychodynamic; Psychotherapy; Attachment.

Received: June 13, 2021 Revised: July 1, 2021 Accepted: July 13, 2021

Address for correspondence: Myung Seon Song, MD

Department of Psychiatry, Keyo Hospital, 15 Ojeon-ro, Uiwang 16062, Korea

Tel: +82-31-455-3333, Fax: +82-31-452-4110, E-mail: msfloat@hanmail.net

\section{서 론}

치료 순응도(treatment adherence)란 한 개인의 행동이 의 료진의 권고와 얼마나 일치하는가의 정도를 뜻하는 말로써 (Lee 등 2010), WHO는 "합의된 의료인의 권고안에 환자의 행동-약물 복용, 식이 요법, 생활 습관 변화 등-이 얼마나 부합하는가의 정도”로 정의하였다(World Health Organization 2003). 예를 들어, 환자가 하루 4번 1개씩 일주일 동안 복용하도록 처방 받은 약물을 5일간 하루 1 번 2개씩 복용했

This is an Open Access article distributed under the terms of the Creative Commons Attribution Non-Commercial License (https://creativecommons.org/licenses/by-nc/4.0) which permits unrestricted non-commercial use, distribution, and reproduction in any medium, provided the original work is properly cited.
다면, 이때의 순응도는 36\% (10/28)가 된다(McDonald 등 2002). 약물 비순응은 보통 처방된 약물 용량의 $80 \%$ 미만을 복용하는 것으로 정의되지만, 처방된 용량보다 너무 많은 양 을 복용하는 것도 비순응에 해당된다(Nieuwlaat 등 2014). 낮은 순응도는 치료의 효과를 낮추는 것으로 이어지지만, 약 물 순응도에 관한 여러 연구에서 많은 환자들이 약물 치료 를 시작한 1 개월 안에 임의로 투약을 중단하는 것으로 나타 났다(Gialamas 등 2009; Sackett와 Snow 1979). 또, 약물을 지속해서 복용하더라도 처방된 대로 일관성 있게 복용하지 않는 경우도 흔해, 대략적으로 약물 순응도의 범위는 평균 $50 \%$ 정도로, $0 \%$ 에서 $100 \%$ 에 이르기까지 다양하다(Haynes 등 1979; Nieuwlaat 등 2014). 특히, 정신과적 질환을 가진 환자들이 다른 신체 질환을 가진 환자들에 비해 약물 비순 
응이 흔한 것으로 알려져 있다(Blackwell 1973; McDonald 등 2002). 약물 비순응은 건강 상태의 악화, 치료와 연관된 부작용의 증가, 사망률 증가와 연관된다(Nieuwlaat 등 2014; World Health Organization 2003).

약물 순응도를 향상시키기 위한 교육과 전화 상담 등 여 러 중재들이 시도되었지만, 특정한 방법이 효과적이라고 알 려진 것은 없다(McDonald 등 2002; Nieuwlaat 등 2014). Jin 등(2008)은 약물을 포함한 치료 비순응과 연관된 요인들은 크게 5 가지로 나눌 수 있다고 했다. 첫째, 환자 중심 요인들 은 인구학적 특성들(연령, 인종, 성별, 교육 수준)과 심리사 회적 인자들(신념, 동기, 태도), 환자-치료자 관계, 신체적 장애, 건강에 대한 지식 수준, 흡연과 음주, 건망증, 좋은 순 응도의 과거력 등이 있다. 둘째, 치료와 연관된 인자들은 투 약 경로, 치료의 복잡성, 치료 기간, 약물 부작용, 행동 변화 가 요구되는 정도, 약물의 맛, 약물 보관 방법 등이 있다. 셋 째, 질병의 증상과 중증도가 연관이 있다. 넷째, 의료 제도, 다섯 번째로 사회 경제적인 요인들이 영향을 미치는 것으로 나타났다. Mintz와 Flynn(2012)은 약물 치료에 대한 반응을 예측할 수 있게 해주는 특성들로 환자의 애착 유형, 방어기 제, 신경증(neuroticism), 통제 위치(locus of control), 치료 에 대한 기대, 약물에 대한 양가 감정, 변화할 준비가 된 정 도, 치료 선호도 등을 들었다. 위에 언급된 순응도에 영향을 주는 인자들 중 연령, 성별과 같이 바꿀 수 없는 요인들도 있 지만, 환자의 동기, 신념과 같은 심리적 요인, 환자-치료자 관계, 애착 유형, 방어기제, 신경증은 변화시킬 수 있는 요인 들이다. 치료자들이 순응도 향상을 위해 흔히 사용하는 심리 교육(psychoeducation)과 동기강화면담(motivational interview)은 언급된 변화 가능한 요인들 중 일부에 영향력이 있 다는 연구 결과가 있다(Kemp 등 1998). 하지만, 환자-치료 자 관계, 애착 유형, 방어기제, 신경증 등은 정신역동에 대한 이해 없이는 변화를 가져오기 어려운 요인들이다. 정신역동 적 정신치료에서도 환자는 치료에 저항을 보이고, 치료를 임 의로 중단하기도 하는데, 이러한 저항을 극복하고 치료를 지 속하게 하는 것이 정신역동적 정신치료의 중요한 과정이다. 정신역동적 정신치료에서는 환자의 정신역동을 이해하고 그에 맞는 중재를 함으로써 저항을 극복한다. 저자들은 약물 치료에서도 관련된 정신역동을 이해하는 것이 약물 순응도 향상에 도움이 될 것이라고 생각한다. 환자의 정신역동으로 인한 약물 불순응의 가능성을 고려하지 못하는 치료자라면, 환자의 불순응을 단순한 동기 부족이나, 치료자의 권위나 능 력에 대한 도전이나 불신으로 받아들이기 쉽고, 결과적으로 치료동맹이 약화되어 치료순응도가 저하되는 악순환으로 이어질 수 있을 것이다.
정신역동과 정신약물의 관계에 대해 이전 연구들이 있지 만, 주로 정신과 치료의 주류가 약물치료로 옮겨 가면서 정 신역동적 정신치료의 비중이 낮아진 시대적 배경 속에서 약 물치료의 한계를 강조하거나, 정신치료와 약물치료를 병용 하는 것이 더 좋은 치료 성과를 내는 것에 초점을 두고 있다 (Busch와 Sandberg 2016; Thase 2000; Winston 등 2005). 정신역동적 정신약물 치료에 관한 연구 중에서 약물 치료 순응도에 초점을 둔 연구는 드물다. 본 논문에서는 약물 치 료 순응도에 중점을 두고 관련된 정신역동 이론을 살펴보고, 정신역동적 정신치료를 할 때만이 아니라 일반적인 외래 치 료를 할 때도 정신역동적 지식과 기법을 활용하면 약물 순 응도를 향상시킬 수 있음을 살펴보고자 한다.

\section{본 론}

\section{약물의 정신역동적 의미}

치료자가 약물을 처방하는 목적은 환자의 증상으로 인한 고통을 경감시키기 위함이고, 환자도 의식적으로는 그 사실을 알고 있지만, 무의식적으로는 다른 여러 의미를 가질 수 있다. 환자와 치료자가 약물에 부여하는 정신역동적 의미는 개인에 따라 다르겠지만, 대표적인 몇 가지를 살펴보는 것이 개개인 의 정신역동적 의미를 이해하는 데 도움이 될 수 있을 것이다.

\section{이행기 대상(Transitional object)으로써의 약물}

이행기 대상은 Winnicott(1971)이 제안한 개념으로, 아이 가 어머니로부터 더 오래 떨어져 있을 수 있도록 도와주는, 아이를 안정시켜주는 물건을 지칭한다. 약물을 이러한 이행 기 대상(transitional object)으로 보는 관점이 있는데, 치료 자와 떨어져 있는 기간 동안 약물이 마음을 안정시키고, 불 안을 완화시키는 기능에 초점을 두고 치료자의 상징적 대체 물로 보는 것이다(Adelman 1985; Hausner 1985). 이때 약물 은 치료자의 환자에 대한 돌봄을 상징하는 것으로 약물을 복 용하는 행위는 스스로를 돌보는 행위이자 돌봄을 받는 행위 가 되는 것이다(Li 2010; Tutter 2006). 약물이 이행기 대상임 을 보여주는 예로서 정신과 전공의들이 교체되는 시기에 새 로운 전공의가 입원 환자들의 약물을 변경하려고 할 때 이해 할 수 없을 정도로 강렬한 저항에 부딪히는 경우를 들 수 있 다. 이는 환자들에게 약물이 떠나간 전공의를 상징하는 대상 이기 때문이다(Gutheil 1982). 또 다른 예로 우울증이 호전되 었음에도 치료를 중단하려고 하면 불안이 심해지면서 증상 이 악화되어 항우울제를 끊지 못하는 환자에서도 볼 수 있 다. 이때 약물은 환자에게 치료자와의 관계가 지속되게 해주 는 상징적인 이행기 대상일 수 있다. 이러한 환자는 치료자 
를 자주 보지 못하더라도 투약을 함으로써 치료자와 함께 한다고 느낄 수 있다. 뿐만 아니라, 어떤 환자들은 약물을 절 대 복용하지 않지만 가지고 다니는 것만으로도 비슷한 위안 을 얻기도 한다(Book 1987).

\section{자기 대상(Selfobject)으로써의 약물}

자기 대상(selfobject)은 아이의 자기(self) 발달을 위해 필 수적인 거울(mirroring) 역할과 이상화(idealization)를 해주 는 중요한 타인을 지칭하는 용어이다. 이를 통해 아이는 경험 을 내면화해서 자기를 발전시킬 수 있다(Kohut 1971). 약물 은 자기 대상의 대체물로 사용될 수 있다. 약물을 처방 받는 것은 자신의 고통에 대해 어떤 조치가 취해졌다는 구체적인 흔적이다. 이는, 자신의 고통이 타당한 것이라고 인정받고, 중요하게 여겨진다는 의미로 받아들여진다. 또, 환자는 치료 자를 이상화하듯이 약물을 이상화해서 그와 동일시하여 안 전감과 힘을 가진 느낌을 받을 수 있다(Li 2010; Tutter 2006)

\section{약물의 전이와 역전이}

환자 측면에서는 전이의 영향이 있을 수 있다. 이때 전이 는 치료자에 대한 전이와 약물에 대한 전이 두 가지가 있을 수 있다. 치료자에 대한 전이는 양육자와의 관계의 문제를 활성화시키는 경우가 흔하다. 한 예로 우는 아이의 마음에 관심을 가지고 공감해주기보다는 과자나 장난감을 제공해 서 울음을 빨리 그치게 하기에 급급했던 양육자 밑에서 자 란 환자의 경우를 들 수 있다. 이러한 환자는 치료자가 약물 을 처방하는 것이 치료자도 양육자처럼 자신의 고통에 공감 하기보다 약물로 고통의 표현을 막는 것이라고 느낄 수 있 다. 반대로, 아이가 울 때 달래기 위한 물건을 제공했든 안 했든 간에 정서적 고통에 대한 공감을 충분히 받으면서 자 란 환자는 치료자가 환자의 고통에 공감하는 것을 받아들이 기 더 쉬울 것이다. 때문에 약물에 대해서도 치료자가 구체 적인 사물의 형태의 돌봄으로 처방한 것이라고 느낄 수도 있다(Blackwell 1973; Li 2010). 약물 자체에 대한 전이의 예 로는 위약반응(placebo)을 들 수 있다. 환자가 약물을 복용 하자마자 즉각적인 효과를 느낀다면 이는 위약반응으로 설 명할 수 있다. 반대로 부정적 전이가 있다면 약물을 복용하 자마자 부작용을 느끼거나 하는 노세보(nocebo)효과로 나 타날 수도 있다. 동일한 성분과 용량의 약물임에도 약의 모 양이 달라진 것만으로 부작용을 호소하거나, 효과가 떨어진 다고 호소하는 경우가 예가 될 수 있을 것이다. 앞서 언급한 약물의 이행기 대상 기능도 일종의 약물에 대한 전이로도 볼 수 있다. 치료자가 처방해준 약물을 복용함으로써 치료자 가 부재중일 때도 환자는 치료자와 연결되어 있다는 느낌을
받고, 치료자가 없는 시간을 극복한다(Gabbard 2014).

역전이에 의한 약물 처방은 환자의 경험이 아니라 치료자의 경험에 초점을 두고 약물을 처방하는 것이다(Mintz와 Flynn 2012). 치료자가 약물을 처방하는 것은 일종의 행동화(enactment)로 볼 수 있다(Li 2010). 행동화는 치료자와 환자 사이 의 상호작용이 언어가 아니라 행동으로 나타나는 것을 지칭 한다(McLaughlin 1991). 예를 들면, 극심한 불안을 호소하 는 공황장애 환자에게 치료자가 평소와 달리 고용량의 벤조 디아제핀을 처방하는 경우처럼 환자가 겪는 극심한 고통이 치료자에게 심한 역전이적 불안을 일으켜 과도한 약물 처방 으로 이어지는 경우를 들 수 있다(Milrod와 Busch 1998). 반 대로, 치료자가 환자에 대해 화가 난 감정을 행동화해서 환자 가 필요한 양보다 약물의 처방을 줄이거나, 약물을 장기 처방 해서 환자를 만나는 것을 피하는 경우도 있다(Rubin 2001).

\section{증상에 대한 정신역동과 치료순응도와의 관계}

일부 환자들은 여러 의식적, 무의식적인 이유로 증상을 포 기할 수 없기 때문에 치료에 순응하지 않고, 그 결과 질환의 호전을 방해하게 된다. 질환을 않음으로써 신경증 환자는 정 신적 갈등을 해결하지 않고 갈등으로 인한 불안에서 벗어나 고 증상으로 도피하여 정신적 노력을 최소화할 수 있는 무 의식적 이득이 있는데 이를 일차이득(primary gain)이라고 한다. 예를 들어, 오른손으로 부인을 살해한 남편이 오른팔 이 마비되는 전환증상(conversion)을 일으킨 경우, 증상을 통해 죄책감과 정신내적 갈등에서 벗어나게 되어 불안이 감 소되는 것 같은 것이다(Fishbain 1994; Laplanche와 Pontalis 1973). 일차이득이 증상 자체의 형성에 기여하는 것과 달 리 이차이득(secondary gain)은 증상이 생긴 후 증상으로 인 해 학교를 결석한다거나 직장을 결근하는 것처럼, 하고 싶지 않은 의무를 면제 받는 것과 같은 이득을 말한다(Laplanche 와 Pontalis 1973). 이차이득이 있는 환자의 경우 치료 효과 가 낮은 것으로 알려져 있는데, 정신과 치료 외래 환자들의 $40 \%$ 이상이 이차이득에 대한 기대를 가지고 병원에 오지만 치료자는 이에 대해 잘 알지 못한다는 연구결과가 있다(van Egmond 등 2002; 2005). 이렇게 이차이득의 문제가 잘 다뤄 지지 않은 환자의 경우 약물 처방을 받더라도 꾸준히 복용 하지 않을 가능성이 높다.

질환에 걸렸음을 부정하는 것도 약물 순응도를 낮추는 요 인이 된다. 정신병적 질환을 않는 환자들은 병식 결여로 투 약을 거부하곤 한다. 비정신병적 정신질환 환자들도 정신치 료는 받더라도 약물 치료는 거부하는 경우들이 종종 있다. 이들은 낙인(stigma)에 대한 두려움으로 타인이 자신을 환자 로 바라보는 것을 피하기 위해서 거부하기도 하고, 약물을 
복용하는 것이 스스로를 심한 장애를 가졌다고 느끼게 하는 것을 피하기 위해서 거부하기도 한다(Gabbard 2014).

\section{애착과 치료 순응도}

애착이론에 따르면 영유아기 양육자와의 경험이 인지적인 모델로 내재화되어 성인기에 타인과의 상호작용을 어떻게 하는지에 영향을 미친다고 한다(Bowlby 1973). Ainsworth 등(1978)의 이론에 기반하여, 영아에 대한 관찰 실험을 통해 3 가지 애착유형을 제시했다. 안정 애착(secure attachment) 과 회피형(avoidant)과 양가형(ambivalent)의 2가지 불안정 애착이다. 어린 시절의 애착 유형은 성인기의 행동 패턴과 인격 특성에 영향을 미치는 것으로 나타났다. 안정 애착형 아동은 회복 탄력성이 있는 유능하고 따듯한 공감 능력이 있는 성인으로 자라났다. 회피형 애착을 가진 경우 침울하거 나 거만하고, 반항적인 행동을 보였으며 강박적, 자기애적, 분열성 인격 특성을 가졌다. 양가형 애착을 가진 사람은 집 착하고, 미숙한 행동을 보였으며 연극성 인격 특성을 보였다 (Alfonso 2009; Wallin 2007).

애착 유형에 따라 치료 순응도에 차이가 있는지 살펴본 연 구들이 있는데, 공통적으로 회피형 애착 유형이 다른 애착 유 형들보다 치료 순응도가 낮은 것으로 나타났다(Ciechanowski 등 2004; Ciechanowski 등 2001). 회피형 애착을 가진 사람 은 한 번이라도 기대에 못 미치면 상대와의 관계를 쉽게 단절 하는 경향이 있어, 약물 치료에서도 마찬가지로 실망스러운 점이 조금이라도 있으면 치료를 중단하기 쉬울 수 있다 (Mintz와 Flynn 2012). 또한, 회피형 애착을 가진 사람은 타 인을 신뢰하는데 어려움이 있어, 타인의 도움을 받는 것을 불 편해하고, 독립적인 것을 선호하는 것도 영향이 있을 것이다.

\section{약물 순응도 향상을 위한 정신역동적 접근}

앞서 기술한 바와 같이, 같은 약물 처방이라도 개별 환자 들에게는 다른 의미로 여겨질 수 있는 것을 치료자가 알고 있는 것이 중요하다. 예를 들어, 약물을 이행기 대상이나 자 기 대상으로 여기는 환자라면 약물 치료에 대한 순응도가 높을 것으로 예상할 수 있을 것이다. 또, 환자가 치료자에 대 한 긍정적인 전이를 가지고 있다면 약물도 긍정적으로 수용 할 가능성이 높다. 반면에 부정적인 전이가 우세하다면 약물 에 대해서도 거부감이 클 것이다. 따라서 치료자는 환자가 약물에 대해 어떻게 받아들이고 있는지, 치료자와 환자 사이 의 관계와 치료적 동맹이 어떤 상태인지 파악해야 한다.

조현병 환자들에서 좋은 치료 동맹이 더 나은 약물 순응도 와 상관 관계를 보인 연구가 있고(Chang 등 2019), 우울증 치 료에서 약물치료와 정신치료를 병행한 치료가 단독치료보다
효과적이었을 뿐만 아니라, 정신치료를 병행한 경우가 환자들 의 치료 탈락률이 낮다는 연구가 있다(Pampallona 등 2004). 즉, 정식 정신치료가 아니어도 약물 치료의 정신치료적 측면 에 관심을 가지면 더 나은 치료 동맹을 갖고 순응도를 향상 시킬 수 있음을 알 수 있다(Gabbard 2014). 따라서 본격적인 정신역동적 정신치료를 하지 않는 환자에 대해서라도 정신 역동적 공식화(psychodynamic formulation)가 도움이 될 수 있다. 환자의 정신역동에 대해 치료자가 알고 있으면 환 자에게 공감적 태도를 유지하는데 도움이 될 뿐만 아니라 (Treloar 2009), 치료자가 환자에게 역전이에 의한 행동화로 약물을 처방하는 것도 줄일 수 있다. 이때의 정신역동적 공 식화는 길고 상세하지 않더라도, 환자의 치료자와 약물에 대 한 관계를 담은 간략한 것만으로도 충분히 도움이 된다. 이러 한 정식역동적 공식화는 다른 치료자가 해당 환자를 진료할 때에도 참고할 수 있는 자료가 된다(Mintz와 Flynn 2012).

약물 치료를 위한 정신역동적 공식화에는 약물과 질환의 정신역동적 의미, 전이, 역전이, 애착유형 등이 포함될 수 있 다. 이를 작성하기 위해서는 일반적인 과거력 청취에 더해 환자가 약물에 대해 어떻게 생각하고 있는지에 대한 질문, 특 히 양가감정을 다루기 위해서는 구체적인 질문이 필요하다. 일반적인 질문을 한 경우 환자들 중 $2 \%-4 \%$ 만 양가감정을 인 지한다고 답했으나, "부작용이 발생하면 투약을 그만둘 가능 성이 얼마나 되는지?'와 같이 구체적으로 질문하면, 23\%-36\% 의 환자가 약물에 대한 양가 감정에 대해 답했다. 환자들은 치료자에 대한 질문보다 약물에 대한 질문에 더 쉽게 답하는 경향이 있다고 한다. 따라서, 약물에 대해 먼저 다루고, 이후 치료자에 대한 생각과 느낌을 다루는 것이 좀 더 편한 접근 법이 될 것이다(Warden 등 2009). 이 과정에서 치료자나 약 물에 대한 부정적인 전이가 더 큰 것으로 파악된다면, 치료 자는 부정적 전이로 인한 저항을 해소하기 위한 중재를 시 행해야 할 것이다. 이때 치료자는 환자의 저항에 대해 비난 하지 않고, 저항의 근원에 대한 호기심을 가지고, 저항을 이 해하기 위해 환자의 도움을 청해야 한다(Gabbard 2014).

치료자의 환자에 대한 역전이도 반드시 탐색해서 치료에 어떤 영향을 주는지 알고 있어야 할 것이다. 치료자의 역전 이로 인해 환자에게 불필요한 약물을 처방하거나, 반대로 필 요한 약물을 주지 않을 수 있기 때문이다(Rubin 2001). 이차 이득으로 인해 치료저항성을 보이는 환자의 치료자는 좌절 감을 느끼기 쉬워 환자에게 공감하기 어렵게 되고, 역전이에 따른 처방을 하기 쉬워진다. 이때 치료자가, 환자가 환자 역 할(sick role)을 통해 얻는 이득에 비해 심리적, 사회적으로 횔씬 큰 대가를 치르고 있음을 염두에 두면 환자에 대한 공 감과 연민을 유지하기 쉬워진다. 치료자는 비판단적인 개방 
형 질문을 이용해서 환자의 현재 상황과 무의식적인 동기를 파악하고, 환자 스스로 치료를 방해하는데 기여하는 부분을 알 수 있고, 그로 인해 손해를 보고 있음을 깨닫도록 도울 수 있다(Kwan와 Friel 2002; Mintz와 Flynn 2012).

환자가 어떤 애착 형태를 보이는지 파악하는 것도 도움이 된다. 회피형 애착을 가진 사람들은 독립성을 중시하기 때문에 치료자가 환자와 협의하여 약물 치료에 대한 결정을 내리는 것 이 순응도 향상에 도움이 될 수 있을 것이다(Alfonso 2009). 회 피형 애착을 가진 환자 사이에서 일어나는 통제(control)와 주도권 싸움에 대해 치료자가 잘 파악하고 있어야 하며, 따 듯하고 협동적인 자세를 취하는 것이 권위적이고 거리를 두 는 태도보다 효과적일 것이다(Wallin 2007).

\section{결 론}

낮은 약물 순응도는 건강 상태의 악화, 증상의 재발과 같 은 부정적인 결과를 낳는다. 본 연구에서는 약물 순응도와 연관된 정신역동에 대해 알아보고 정신역동적 지식과 기법 을 이용하여 어떻게 약물 순응도를 향상시키는지 보여주고 자 하였다. 약물치료 위주의 치료에서도 약물과 관련된 내용 에 중점을 두고 약물과 질환의 정신역동적 의미나, 전이, 역 전이, 애착 유형 등에 대한 간략한 정보를 담은 정신역동적 공식화를 작성하는 것은 치료 순응도를 향상시키는데 도움 이 될 수 있다. 약물은 이행기 대상이나 자기대상과 같이 환 자에게 긍정적 의미를 갖는 경우도 있지만, 환자의 부정적 전이의 대상이 되거나, 치료자의 부정적 역전이가 행동화된 결과물일 수도 있다. 또, 환자가 가진 애착 유형에 따라 약물 순응도가 달라질 수 있는데, 특히 회피형 애착 유형이 낮은 순응도를 보이는 것으로 나타났다. 치료자는 환자가 약물과 치료자에 대해 어떤 정신역동적 의미를 부여하고 있는지, 치 료 동맹이 어떤 상태인지 잘 파악하고 그에 따라 적절한 중 재를 하여 순응도를 낮추는 저항을 해소하는 것이 필요할 것이다. 회피형 애착을 가진 환자에 대해서는 치료자가 특히 따듯하고 협동하는 자세를 가지고 대하여, 환자가 고립되어 스스로에게만 의지하는 상태에서 타인과 도움을 주고받을 수 있는 상태로 변할 수 있도록 도와주는 것이 필요하다.

\section{Acknowledgments}

None

\section{Conflicts of Interest}

The authors have no potential conflicts of interest to disclose.

\section{Author Contributions}

Conceptualization: Myung Seon Song. Data curation: Myung Seon Song. Formal analysis: Myung Seon Song. Funding acquisi- tion: Soo-Bong Jung. Investigation: Soo-Bong Jung. Methodology: Myung Seon Song. Project administration: Myung Seon Song. Resources: Soo-Bong Jung. Supervision: Myung Seon Song. Validation: Myung Seon Song. Visualization: Myung Seon Song. Writingoriginal draft: Myung Seon Song, Soo-Bong Jung. Writing — review \& editing: Myung Seon Song, Soo-Bong Jung.

\section{ORCID iDs}

Myung Seon Song https://orcid.org/0000-0001-5036-6279

Soo-Bong Jung https://orcid.org/0000-0003-2301-2779

\section{REFERENCES}

Adelman SA. Pills as transitional objects: a dynamic understanding of the use of medication in psychotherapy. Psychiatry 1985;48:246-253.

Ainsworth MDS, Blehar MC, Waters E, Wall S. Patterns of attachment: a psychological study of the strange situation. Hillsdale, NJ: Lawrence Erlbaum Associates; 1978

Alfonso CA. Dynamic psychopharmacology and treatment adherence. J Am Acad Psychoanal Dyn Psychiatry 2009;37:269-285.

Blackwell B. Drug therapy: patient compliance. N Engl J Med 1973;289: 249-252.

Book HE. Some psychodynamics of non-compliance. Can J Psychiatry 1987;32:115-117

Bowlby J. Attachment and Loss. Volume II. Separation, anxiety and anger. London: The Hogarth press and the Institute of Psycho-analysis; 1973.

Busch FN, Sandberg LS. Psychotherapy and medication: the challenge of integration. London: Routledge;2016.

Chang JG, Roh D, Kim CH. Association between therapeutic alliance and adherence in outpatient schizophrenia patients. Clin Psychopharmacol Neurosci 2019;17:273-278.

Ciechanowski P, Russo J, Katon W, Von Korff M, Ludman E, Lin E, et al. Influence of patient attachment style on self-care and outcomes in diabetes. Psychosom Med 2004;66:720-728.

Ciechanowski PS, Katon WJ, Russo JE, Walker EA. The patient-provider relationship: attachment theory and adherence to treatment in diabetes. Am J Psychiatry 2001;158:29-35.

Fishbain DA. Secondary gain concept: definition problems and its abuse in medical practice. APS J 1994;3:264-273.

Gabbard GO. Psychodynamic psychiatry in clinical practice. 5th ed. Washington, DC: American Psychiatric Publshing;2014.

Gialamas A, Yelland LN, Ryan P, Willson K, Laurence CO, Bubner TK, et al. Does point of care testing lead to the same or better adherence to medication? A randomised controlled trial: the poct in general practice trial. Med J Aust 2009;191:487-491.

Gutheil TG. The psychology of psychopharmacology. Bull Menninger Clin 1982;46:321-330.

Hausner RS. Medication and transitional phenomena. Int J Psychoanal Psychother 1985;11:375-398.

Haynes RB, Taylor DW, Sackett DL. Compliance in health care. Baltimore, MD: Johns Hopkins University Press;1979.

Jin J, Sklar GE, Min Sen Oh V, Chuen Li S. Factors affecting therapeutic compliance: a review from the patient's perspective. Ther Clin Risk Manag 2008;4:269-286.

Kemp R, Kirov G, Everitt B, Hayward P, David A. Randomised controlled trial of compliance therapy. Br J Psychiatry 1998;172:413-419.

Kohut H. The analysis of the self: a systematic approach to the psychoanalytic treatment of narcissistic personality disorders. Chicago, IL: University of Chicago Press; 1971.

Kwan O, Friel J. Clinical relevance of the sick role and secondary gain in the treatment of disability syndromes. Medical Hypotheses 2002;59: 129-134. 
Laplanche J, Pontalis JB. The language of psycho-analysis. London: W. W. Norton; 1973.

Lee MS, Ko YH, Joe SH. Treatment compliance of antidepressants. Korean J Biol Psychiatry 2010;17:5-14.

Li TCW. Psychodynamic aspects of psychopharmacology. J Am Acad Psychoanal Dyn Psychiatry 2010;38:655-674.

McDonald HP, Garg AX, Haynes RB. Interventions to enhance patient adherence to medication prescriptions: scientific review. JAMA 2002; 288:2868-2879.

McLaughlin JT. Clinical and theoretical aspects of enactment. J Am Psychoanal Assoc 1991;39:595-614.

Milrod BL, Busch FN. Combining psychodynamic psychotherapy with medication in the treatment of panic disorder: exploring the dynamic meaning of medication. Psychoanal Inq 1998;18:702-715.

Mintz DL, Flynn DF. How (not what) to prescribe: nonpharmacologic aspects of psychopharmacology. Psychiatric Clin North Am 2012;35: 143-163.

Nieuwlaat R, Wilczynski N, Navarro T, Hobson N, Jeffery R, Keepanasseril $\mathbf{A}$, et al. Interventions for enhancing medication adherence. Cochrane Database Syst Rev 2014;(11):CD000011.

Pampallona S, Bollini P, Tibaldi G, Kupelnick B, Munizza C. Combined pharmacotherapy and psychological treatment for depression: a systematic review. Arch Gen Psychiatry 2004;61:714-719.

Rubin J. Countertransference factors in the psychology of psychopharmacology. J Am Acad Psychoanal 2001;29:565-573.

Sackett D, Snow J. The magnitude of adherence and nonadherence. In:
Haynes RB, Taylor DW, Sackett DL. Compliance in health care. Baltimore, MD: Johns Hopkins University Press;1979. p.11-22.

Thase ME. Psychopharmacology in conjunction with psychotherapy. In: Snyder CE, Ingram RE. Handbook of psychological change: psychotherapy processes and practices for the 21st century. New York: John Wiley \& Sons Inc;2000. p.474-497.

Treloar AJC. Effectiveness of education programs in changing clinicians' attitudes toward treating borderline personality disorder. Psychiatr Serv 2009;60:1128-1131.

Tutter A. Medication as object. J Am Psychoanal Assoc 2006;54:781804.

van Egmond J, Kummeling I. A blind spot for secondary gain affecting therapy outcomes. Eur Psychiatry 2002;17:46-54.

van Egmond J, Kummeling I, Balkom TA. Secondary gain as hidden motive for getting psychiatric treatment. Eur Psychiatry 2005;20:416421.

Wallin DJ. Attachment in psychotherapy. New York: Guilford press;2007.

Warden D, Trivedi MH, Wisniewski SR, Lesser IM, Mitchell J, Balasubramani GK et al. Identifying risk for attrition during treatment for depression. Psychother Psychosom 2009;78:372-379.

World Health Organization. Adherence to long-term therapies: evidence for action. Geneva, Switzerland: World Health Organization;2003.

Winnicott DW. Playing and reality. London: Tavistock Publications;1971.

Winston A, Been H, Serby M. Psychotherapy and psychopharmacology: different universes or an integrated future? J Psychother Integr 2005; 15:213-223. 